\title{
Primer registro para Chile de Nyctelia discoidalis Fairmaire, 1905 (Coleoptera: Tenebrionidae)
}

\author{
First record for Chile of Nyctelia discoidalis \\ Fairmaire, 1905 (Coleoptera: Tenebrionidae)
}

Mauricio Cid-Arcos ${ }^{1} \&$ Álvaro Zúñiga-Reinoso ${ }^{2}$

\section{Resumen}

Se registra por primera vez a Nyctelia discoidalis Fairmaire, 1905, (Coleoptera, Tenebrionidae) en la Patagonia chilena. El registro se obtuvo a partir de ejemplares recolectados en la localidad de Chile Chico, Provincia de General Carrera, Región de Aysén.

\section{Palabras clave:}

Pimeliinae, Nycteliini, Faunística, Patagonia.

\begin{abstract}
Nyctelia discoidalis Fairmaire, 1905, (Coleoptera, Tenebrionidae) is recorded for the first time in the Chilean Patagonia. The record was obtained from specimens collected in Chile Chico, General Carrera Province, Aysén Region.
\end{abstract}

\section{Key words:}

Pimeliinae, Nycteliini, Faunistic, Patagonia.

El género Nyctelia Berthold, 1827 (Tenebrionidae: Pimeliinae: Nycteliini), comprende 66 especies descritas, distribuidas desde el noroeste de Argentina y Chile central hasta el extremo sur de la Patagonia, habitando biomas áridos y semiáridos (Flores, 1997; Flores \& Cheli, 2014; Silvestro \& Flores, 2016). En Chile este género está representado por 17 especies (Peña, 1966; Zúñiga-Reinoso, 2016; Zúñiga-Reinoso \& Jerez, 2012b), distribuidas en las provincias biogeográficas de Santiago, Maule y Patagonia central (Flores, 1997). La mayoría de las especies son abundantes, pudiendo encontrarse más de dos especies en simpatría (Peña, 1963). Debido a lo anterior, es que los rangos de distribución para muchas de las especies de este género son poco claros, lo que ha generado problemas al momento de definir la diversidad de este grupo en Chile (Zúñiga-Reinoso \& Jerez, 2012a, 2012b; ZúñigaReinoso, 2016).

El objetivo del presente trabajo es entregar el primer registro de Nyctelia discoidalis Fairmaire, 1905 en la estepa patagónica de Chile.

Los ejemplares fueron identificados siguiendo a Kulzer (1963). El material examinado se encuentra depositado en las siguientes colecciones: Museo de Zoología, Universidad de Concepción, Concepción, Chile (UCCC); Colección Particular Mauricio Cid, Talca, Chile (CPMC) y Colección Jaime Zavala Benavente (CJZB).

Material examinado: Chile, Región de Aysén del General Carlos Ibáñez del Campo, Provincia de General Carrera: 1ð, Chile, Aisen. $250 \mathrm{msnm}$, Chile Chico, dunes n. lake 463ㄷ- $71^{\circ} 43^{\circ} \mathrm{W}, \quad \mathrm{XI}-21-1966$, Leg. E.I Schlinger \& M.E. Irwin (UCCC); $3 \jmath^{\wedge}$ y 19 , Chile Chico, 26/11/2017, Leg. M. Cid-Arcos (CPMC);

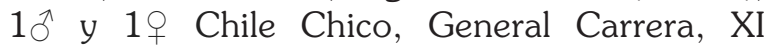
Región Chile, 46³2'16.30”S, 7142'38.26”O,

$1 \quad$ Calle 5 1/2 Norte \#3833, Talca, Chile.

$\triangle$ mauriciocid.4@gmail.com

2 Laboratorio de Genética y Evolución, Facultad de Ciencias, Departamento de Ciencias Ecológicas, Universidad de Chile, Santiago, Chile. 

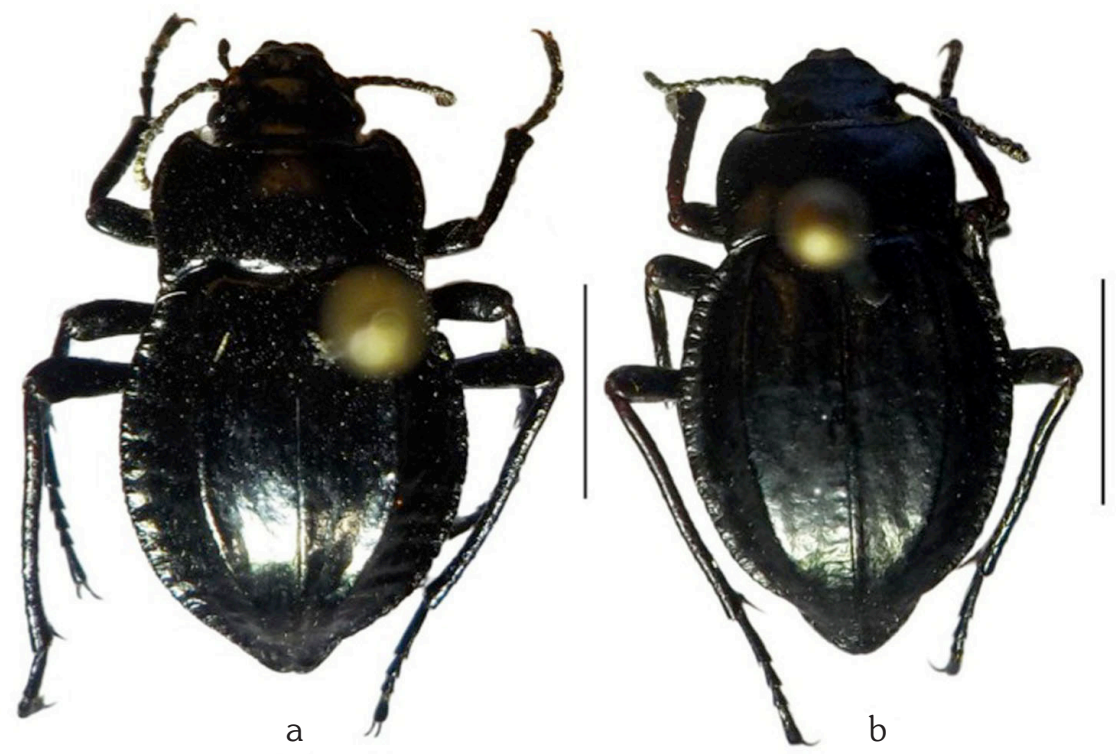

Fig. 1. Habitus vista dorsal de Nyctelia. 1a. Nyctelia discoidalis. 1b. Nyctelia unicosta. Escala: $5 \mathrm{~mm}$.

en arenales al borde del lago, 08/10/2017, Leg. J. Zavala B. (CJZB).

Diagnosis: Largo 13-14 mm, ancho 6-8 $\mathrm{mm}$ (Fig. 1a). Antenas llegan hasta el tercio medial del pronoto. Pronoto con márgenes laterales subparalelos, crenulados y cubiertos por cortas setas esparcidas; ancho máximo en tercio medial, poco notorio. Élitros (Fig. 2a) con una costilla longitudinal marcada; espacio entre costilla

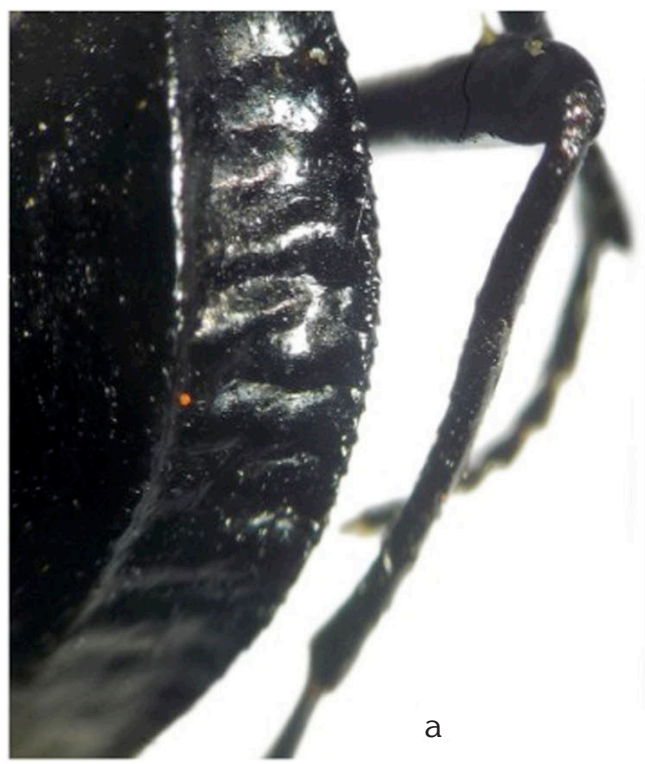

y margen elitral con surcos transversales poco profundos; margen elitral con pequeñas espinas; ápice de forma anguloso.

\section{COMENTARIOS}

Nyctelia discoidalis es una especie semejante a N. unicosta Fairmaire, 1905 (Fig. 1a, 2a), diferenciándose de ésta por los surcos

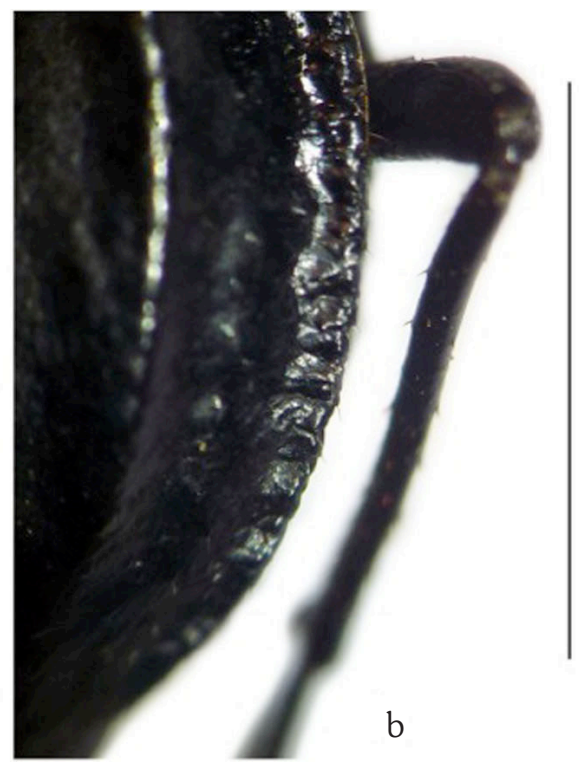

Fig. 2. Detalle del élitro vista dorsal. 2a. Nyctelia discoidalis. 2b. Nyctelia unicosta. Escala: 5 mm. 


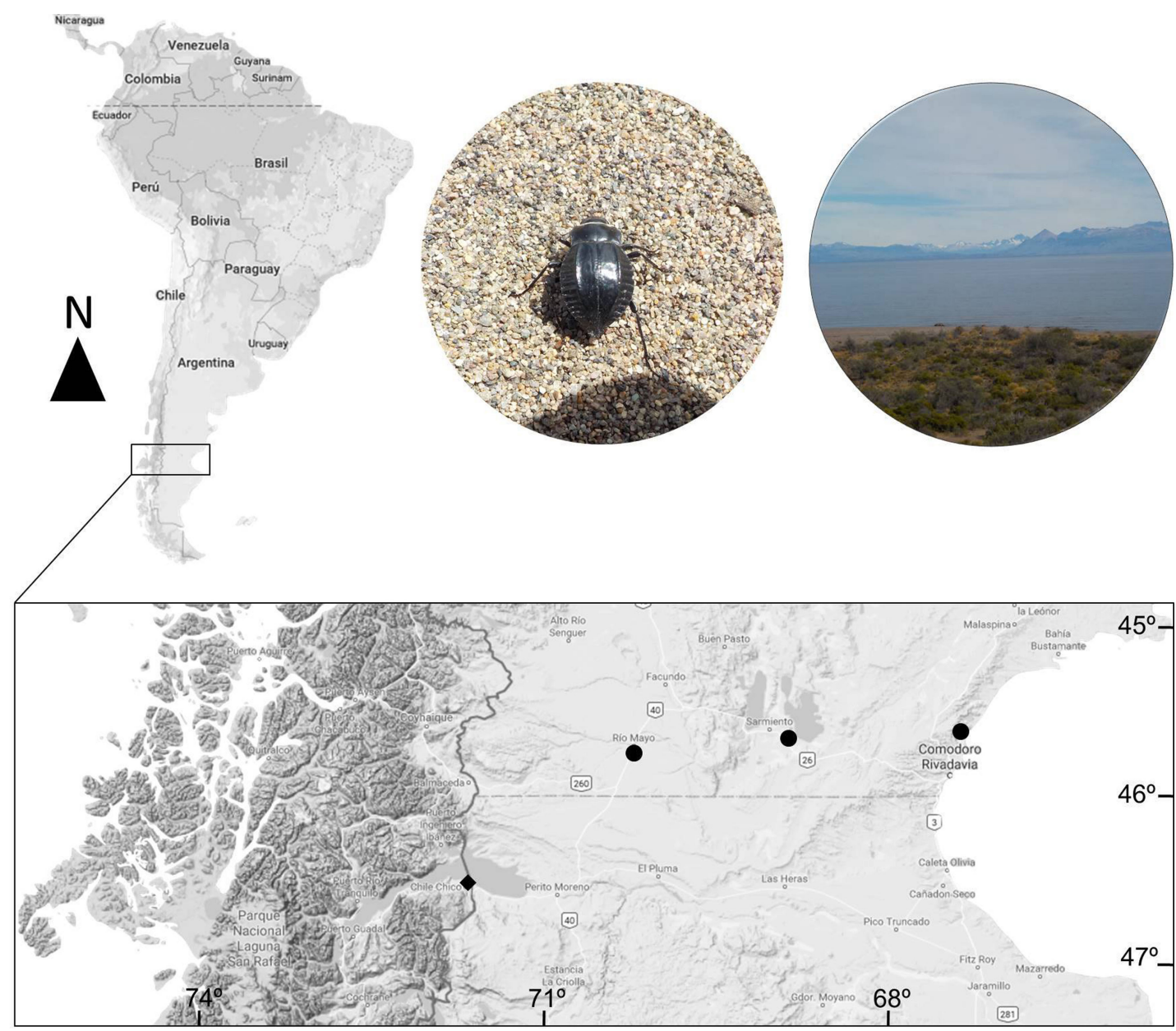

Fig. 3. Mapa de la distribución actual de Nyctelia discoidalis. Círculos representan los registros históricos de $N$. discoidalis, mientras que el rombo representa el nuevo registro.

Fotografías muestran a $N$. discoidalis in situ en un arenal, mientras que la otra muestra el ambiente.

transversales de los élitros, presentes entre la costilla y el margen elitral (Fig. 1b-2b).

Esta especie ha sido recolectada deambulando de día por las dunas cercanas al Lago General Carrera, en los alrededores de Chile Chico (ver en Fig. 3); cohabitando con N. darwini Waterhouse, 1841; N. fitzroyi Waterhouse, 1841; $N$. solieri Waterhouse, 1841 ; y $N$. stephensi Waterhouse, 1841. Esto corrobora lo señalado por Peña (1963), en relación a la simpatría de especies.

Los antecedentes históricos de recolección de este taxón señalan como distribución, algunas localidades de la provincia argentina de Chubut (Kulzer, 1963), por loqueestenuevoregistroextiende el rango de distribución de la especie $\sim 140 \mathrm{Km}$ al
Suroeste, siendo la localidad Río Mayo (ChubutArgentina) la más cercana (Fig. 3). La ausencia de registros de esta especie en la Patagonia chilena, podría deberse tanto, a las pocas expediciones científicas entomológicas que han recorrido la zona, como al estudio superficial del material depositado en las colecciones institucionales. Esto último ha ocurrido en otros casos, como el registro para Chile de N. grandis Fairmaire, 1904 (ZúñigaReinoso, 2016), lo que evidencia la importancia de las colecciones institucionales y la revisión minuciosa de estas. Finalmente, este registro es una pequeña contribución para el conocimiento de la biodiversidad de la estepa patagónica de la Región de Aysén. 


\section{AGRADECIMIENTOS}

Los autores agradecen a Juan Francisco Campodónico por su ayuda en la edición de imágenes y comentarios críticos; al Dr. Jorge Artigas, curador de la colección de la Universidad de Concepción y a Jaime Zavala Benavente, por permitir el acceso a su colección particular.

\section{LITERATURA CITADA}

Flores, G. E. (1997). Revisión de la tribu Nycteliini (Coleoptera: Tenebrionidae). Revista de la Sociedad Entomológica Argentina, 56, 1-19.

Flores, G. E., \& Cheli, G. H. (2014). Two new species of Nyctelia Latreille (Coleoptera: Tenebrionidae) from Argentinean Patagonia with zoogeographical and ecological remarks. Zootaxa, 3765(3), 279-287.

Kulzer, H. (1963). Revision der südamerikanischen Gattung Nyctelia Latr. (Col. Teneb.) (24 Beitrag zur Kenntnis der Tenebrioniden). Entomologische Arbeiten aus dem Museum George Frey, 14, 1-71.

Peña, L. (1963). Las Nyctelia (Coleoptera, Tenebrionidae). Noticiario Mensual del Museo Nacional de Historia Natural, 86, 6-8.
Peña, L. (1966). Catálogo de los Tenebrionidae (Coleoptera) de Chile. Entomologische Arbeiten aus dem Museum George Frey, 17, 397-453.

Silvestro, V. A., \& Flores, G. E. (2016). Notes on types of some species described by Billberg and Germar belonging to the South American genera Scotobius Germar, 1823 and Nyctelia Berthold, 1827 (Coleoptera: Tenebrionidae), with new synonymies and taxonomic implications. Annales Zoologici, 66(4), 653-663.

Zúñiga-Reinoso, A. (2016). Registros aclaratorios en la distribución de dos especies de Nyctelia Latreille (Coleóptera: Tenebrionidae) en Chile. Revista Chilena de Entomología, 41, 70-73

Zúñiga-Reinoso, A., \& Jerez, V. (2012a), Sobre la presencia de Nyctelia fitzroyi Waterhouse, 1981 y Nyctelia solieri Waterhouse, 1841 (Coleoptera: Tenebrionidae) en la Región de Magallanes. Anales del Instituto de la Patagonia, 40(1), 115-118.

Zúñiga-Reinoso, A., \& Jerez, V. (2012b). Revisión del estado taxonómico de Nyctelia multicristata Blanchard, 1846 y descripción de Nyctelia confusa Zúñiga-Reinoso $\mathrm{n}$. sp. (Coleoptera: Tenebrionidae). Gayana (Concepción), 76(1), 38-45. 